\title{
Tubotympanic cholesteatoma
}

\section{Darshini Nagarajah, Mohd Khairi Md Daud, Nur Syazwani Salehuddin, Nik Adilah Nik Othman}

Nagarajah D, Md Daud MK, Salehuddin NS, et al. Tubotympanic Cholesteatoma. Malays Fam Physician. 2021;16(3);123-125.

https://doi.org/10.51866/cr1136

Keywords:

Cholesteatoma, middle

ear, tympanic membrane perforation

\section{Authors:}

\section{Mohd Khairi Md Daud \\ (Corresponding author) \\ M. Med (ORL-HNS) \\ Department of Otorhinolaryngology \\ School of Medical Sciences, Universiti \\ Sains Malaysia, Kubang Kerian \\ Kelantan, Malaysia \\ Email: khairikck@usm.my}

\section{Darshini Nagarajah}

M.D

Department of Otorhinolaryngology School of Medical Sciences, Universiti Sains Malaysia, Kubang Kerian

Kelantan, Malaysia

\section{Nur Syazwani Salehuddin M.D \\ Department of Otorhinolaryngology School of Medical Sciences, Universiti Sains Malaysia, Kubang Kerian Kelantan, Malaysia}

\section{Nik Adilah Nik Othman} M. Med (ORL-HNS)

Department of Otorhinolaryngology School of Medical Sciences, Universiti Sains Malaysia, Kubang Kerian Kelantan, Malaysia

\begin{abstract}
Chronic suppurative otitis media is defined as a chronic inflammation of the mucoperiosteal lining of the middle ear cleft. It is described as a persistent disease that is insidious in onset, often capable of causing severe destruction with irreversible sequelae, and clinically present with hearing loss and discharge. It has been classified into tubotympanic (safe) and atticoantral (unsafe) perforation. Cholesteatoma always occur in the atticoantral type and in marginal perforation. We report a case of cholesteatoma that occurred as a tubotympanic type of perforation.
\end{abstract}

\section{Introduction}

Chronic suppurative otitis media (CSOM) is a longstanding chronic inflammation of the middle ear cleft that involves unrelieved hearing loss and the constant threat of microbial invasion of the middle ear, especially in the poor socioeconomic group. Prevalence surveys revealed that the global burden of illness from CSOM involves 65-330 million individuals with draining ears, of which $60 \%$ suffer from significant hearing loss. ${ }^{1}$ It is the third most common cause of hearing loss in children after impacted wax and otitis media with effusion. ${ }^{2}$ Those who do not receive treatment for this condition may end up with profound hearing loss. ${ }^{3}$ A chronic discharging ear should alert primary care health professionals to investigate further and refer to an otorhinolaryngology (ORL) surgeon for a second opinion. We report a patient who presented with perforation at the pars tensa and was complicated by cholesteatoma formation.

\section{Case Presentation}

We report on a 59-year-old patient who was an active smoker with an unknown medical illness and presented with recurrent left ear discharge associated with reduced hearing and tinnitus since young adulthood. He did not have any active symptoms in the right ear. Regarding the ear discharge, he described it as painless with a copious amount of yellowish, non-foulsmelling discharge that occurs throughout the day. He had experienced reduced hearing in his left ear for 5 years, which worsened during active persistent otorrhea. However, he sought treatment at a private specialist centre when he noticed that the left ear discharge persisted for nearly 1 month. The discharge was not associated with upper respiratory tract infection or allergies. He kept his ears dry and denied using a cotton bud to clean his ears. He further explained that he also had tinnitus that was buzzing in nature with an intermittent high-pitched sound that was non-pulsatile. He was able to sleep at night and there was no noticeable disturbance to his daily activities. He was comfortable using the right ear for his phone conversations. He denied any vertigo, facial weakness, headache and nasal or throat symptoms. On examination, he was alert and conscious with no facial weakness or pain. An anterior rhinoscopy and throat examination revealed normal findings. Otoscopic examination showed a left central perforation with keratin and mucopus with intact pars flaccida (Figure 1). There was a healed perforation on the right tympanic membrane. Pure tone audiometry showed severe conductive hearing loss in the left ear.

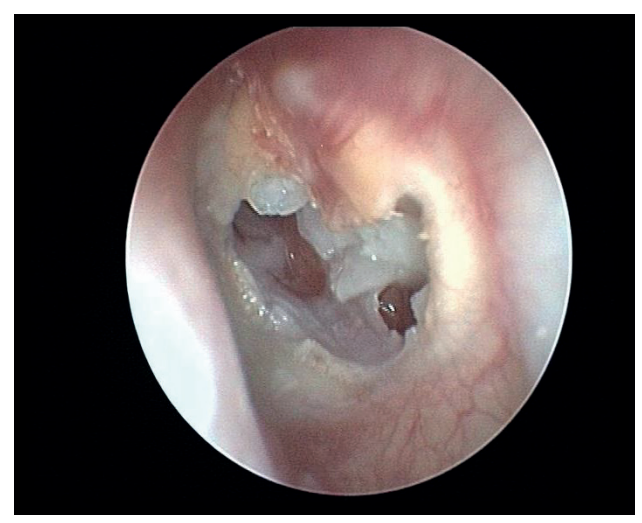

Figure 1. Otoendoscopy of the left ear showed central perforation with keratin debris within the middle ear cavity.

High-resolution computed tomography 
(HRCT) of the temporal bone revealed soft tissue lesions occupying the entire middle ear, aditus antrum and mastoid antrum (Figure 2). There was a remnant of the incus but the remaining ossicles were not visualised.

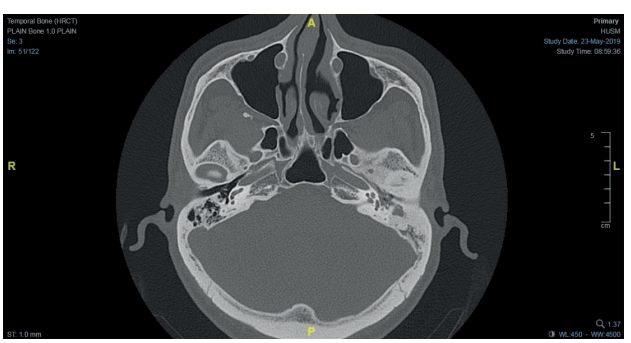

Figure 2. HRCT of the temporal bone. Axial view showing soft tissue lesions occupying the entire middle ear, aditus antrum and mastoid antrum.

The patient underwent left modified radical mastoidectomy and tympanoplasty type 3 for eradication of the disease. The ear was noted to be dry and the mastoid bowl was well epithelised at 1 year post-surgery.

\section{Discussion}

Cholesteatoma is a well-demarcated nonneoplastic lesion producing keratin squamous epithelium in the fibrous tissue matrix with a bony erosion property. It can be further categorised into congenital and acquired. The acquired variety is further subclassified into primary and secondary. ${ }^{4}$

The most common sites of cholesteatoma origin are at the posterior epitympanum, posterior mesotympanum and anterior epitympanum. Secondary cholesteatoma is most commonly observed in attic or marginal perforations. Cholesteatoma occurrence in CSOM with central perforation is very rare and only a few cases have been reported.

Graham et al. first described tympanic membrane cholesteatoma (TMC) in 1984. They noted four cases of TMC with central perforation lined by the undersurface of the tympanic membrane desquamating the epithelial debris into a promontory. ${ }^{5}$ Yamatodani et al. studied 17 cases of secondary acquired cholesteatoma. ${ }^{6}$ They concluded that it is a rare disease that is more prevalent in women than in men and often treated surgically at a relatively advanced age. They also concluded that secondary acquired cholesteatoma is prone to result in poor hearing improvement. In this study, the improvement of postoperative hearing favoured the younger age group.

Furthermore, Bluestone and Klein found that out of 1024 cholesteatoma patients, $6 \%$ had central perforation. ${ }^{7}$ Additionally, Rout et al. described a $3.4 \%$ prevalence of cholesteatoma in the case of CSOM with central perforation in their study. This study also revealed a keratinising squamous epithelium on the tympanic side of the tympanic membrane or in the tympanic cavity, which was occasionally found during surgery. This finding was observed in 28 out of 2948 patients with central perforation and no coexisting pathology suggesting cholesteatoma. ${ }^{8}$ Barath et al. noted that patients with middle ear cholesteatoma presented with a chronic discharging ear in 33-67\% of cases, with hearing loss in $60-80 \%$, facial nerve palsy in $20-64 \%$ and vertigo in $30-60 \%$.

HRCT temporal has been the ideal imaging for diagnosing cholesteatoma due to its excellent spatial resolution and high sensitivity in both the free middle ear and mastoid regions. Typical findings of cholesteatoma have been reported as sharply marginated expansile soft tissue lesions, retraction of the tympanic membrane, scutum blunting and the erosion of the ossicles and tegmen tympani. ${ }^{9}$ CT findings of dehiscent lateral semicircular canal support the diagnosis of labyrinthine fistula with a prevalence of $5-10 \%$ and associations with episodic vertigo, tinnitus and hearing loss.

CSOM is traditionally classified as either atticoantral (unsafe) or tubotympanic (safe). Notably, cholesteatoma is associated with the former type. Since cholesteatoma has recently been discovered to also occur in the pars tensa (albeit rarely), many otologists have described CSOM as a squamous (cholesteatoma) or mucosal disease. The European Academy of Otology and Neurotology and the Japanese Otological Society have jointly classified cholesteatoma as pars flaccida, pars tensa or a combination of both. ${ }^{10}$

\section{Conclusion}

This case study suggests that no perforation is safe in CSOM, including central perforation. Thus, a chronic discharging ear even with tubotympanic perforation should be carefully examined to exclude the possibility of cholesteatoma. 


\section{References}

1. World Health Organization. Chronic Suppurative Otitis Media: Burden of Illness and Management Options. Geneva: World Health Organization; 2004.

2. Md Daud MK, Mohd Noor R, Abd Rahman $\mathrm{N}$, et al. The effect of mild hearing loss on academic performance in primary school children. Int J Pediatr Otorhinolaryngol. 2010;74(1):67-70.

3. Md Daud MK, Othrub KA, Salim R. Bilateral chronic otitis media causing bilateral profound hearing loss. Int Med J. 2012;19(1):84-5.

4. Gupta A, Agarwal SR. A study of the prevalence of cholesteatoma in complications of suppurative otitis media. Indian J Otolaryngol Head Neck Surg. 1998;50(2):140-6.
5. Graham MD, Nelson RA, Kemink JL. Tympanic membrane cholesteatoma (keratoma). Am J Otol. 1984;5(3):175-8.

6. Yamatodani T, Mizuta K, Endo S, et al. Clinical analysis of secondary acquired cholesteatoma. Arch Gen Intern Med. 2017;1(2):12-6.

7. Bluestone CD, Klein JO. Complications and sequelae: Intratemporal. In: Bluestone CD, Klein JO, editors. Otitis Media in Infants and Children. 4th ed. Hamilton: B.C. Decker Inc; 2007. p. 410-1.

8. Rout MR, Mohanty D, Vijaylaxmi Y, et al. Prevalence of cholesteatoma in chronic suppurative otitis media with central perforation. Indian J Otol. 2012;18(1):7-10.
9. Baráth K, Huber AM, Stämpfli P, et al. Neuroradiology of cholesteatomas. Am J Neuroradiol. 2011;32(2):221-9.

10. Yung $\mathrm{M}$, Tono T, Olszewska E, et al. EAONO/JOS joint consensus statements on the definitions, classification and staging of middle ear cholesteatoma. J Int Adv Otol. 2017;13(1):1-8. 